\title{
Rationally Addicted to Drinking and Smoking?
}

\author{
Mikael Bask \\ Department of Economics \\ Umeå University \\ SE-901 87 Umeå, Sweden* ${ }^{* \dagger}$
}

\author{
Maria Melkersson \\ SOFI \\ Stockholm University \\ SE-106 91 Stockholm, Sweden ${ }^{\ddagger}$
}

October 22, 2001

\begin{abstract}
When modeling demand for addictive consumption goods, the most widely used framework is the rational addiction model proposed by Becker and Murphy (1988). In the present paper, we extend the rational addiction model to include two addictive consumption goods, alcohol and cigarettes. We estimate the aggregate demand for alcohol and cigarettes in Sweden, using aggregate annual time series on sales volumes for the period 1955-1999. OLS estimates are compared to GMM estimates allowing for possible endogeneity of lagged and lead consumption. We first estimate demand for alcohol and cigarettes as separate equations. It is found that alcohol demand is quite well described by the rational addiction model while the same is not true for cigarettes. The own-price elasticities are negative, and alcohol demand is more elastic than cigarette demand. The cross-price elasticities are negative, i.e., alcohol and cigarettes are complements. Since consumption of alcohol and cigarettes are probably simultaneous decisions, we estimate the demand for these goods as a system of equations. Alcohol demand is still positively affected by lagged and lead consumption while cigarette demand is not. The obtained elasticities are now generally smaller compared to when estimating the equations separately.
\end{abstract}

\footnotetext{
* Telephone: +46-90-786 78 77, Fax: +46-90-77 23 02, E-mail: mikael.bask@econ.umu.se

$\dagger$ Corresponding author.

$\ddagger$ Telephone: +46-8-16 38 62, Fax: +46-8-15 46 70, E-mail: maria.melkersson@sofi.su.se
} 


\section{Introduction}

When modelling demand for addictive consumption goods, the most widely used framework is the rational addiction model proposed in the seminal paper by Becker and Murphy (1988). ${ }^{1}$ This model has mainly been used to analyze consumption of cigarettes (see, e.g., the overview by Cameron, 1998), but also of such diverse commodities as opium (van Ours, 1995), coffee (Olekalns and Bardsley, 1996) and cinema (Cameron, 1999).

In the present paper, we extend the rational addiction model to include two addictive consumption goods, in our particular example alcohol and cigarettes. Our model is applicable to any situation with two addictive consumption goods, and the generalization to more than two goods is straightforward. We estimate the demand for alcohol and cigarettes in Sweden, using aggregate annual time series on sales volumes for the period 1955-1999. The proposed model enables us to answer interesting questions of major policy relevance. For example, do alcohol and cigarette consumption reinforce each other?

The paper is organized as follows. Section 2 presents the theoretical framework for two addictive consumption goods. In Section 3, we briefly summarize some previous studies on two or more addictive consumption goods. Section 4 presents the data set used together with the empirical results, and Section 5 concludes.

\section{Theoretical framework}

A consumer is said to be addicted to a consumption good, e.g., cigarettes, if an increase in past consumption causes present consumption to rise. ${ }^{2}$ This behavior is usually assumed to involve reinforcement and tolerance. Reinforcement means that an increase in past cigarette consumption increases the craving for present consumption and has the important implication that the consumption of cigarettes at different periods in time are complements. ${ }^{3}$ Tolerance, on the other hand, means that the satisfaction from a given

\footnotetext{
${ }^{1}$ The rational addiction model has been criticized by many (see, e.g., Chaloupka and Warner, 2000). By its critics, the model has been extended to include, for example, learning and regret (Orphanides and Zervos, 1995). Moreover, adjustment costs for a smoker who wants to reduce smoking levels or quit smoking have been proposed (Suranovic et al., 1999).

${ }^{2}$ As in the original model by Becker and Murphy (1988), our model does not explain why people start to use an addictive consumption good in the first place.

${ }^{3}$ Addiction occurs if, and only if, preferences are characterized by adjacent complementarity. The relationship between addiction and adjacent complementarity first appeared implicitly in Ryder and Heal (1973), but was first recognized explicitly in Boyer (1983).
} 
consumption level is lower when past cigarette consumption is greater.

Reinforcement requires that an increase in past cigarette consumption raises the marginal utility of present cigarette consumption. This is also a sufficient condition for addictive behavior if the consumer is myopic. However, rational consumers also consider the future negative consequences of harmful behavior. Reinforcement requires that past cigarette consumption stimulate present consumption by increasing the marginal utility derived from cigarettes by more than the present value is reduced through the marginal harm from future consumption.

Assume a representative consumer with the instantaneous utility function

$$
U[t]=U(a[t], c[t], G[t], H[t], y[t])
$$

where $a[t]$ and $c[t]$ are two addictive consumption goods, alcohol and cigarettes, respectively. $G[t]$ and $H[t]$ are the respective habit stocks which measure the degree of addiction, and $y[t]$ is a composite of non-addictive consumption goods. The habit stocks can simply be interpreted as stocks of alcohol and nicotine dependence, respectively.

The marginal utility derived from drinking and smoking is assumed to be positive, but at a decreasing rate, i.e., $U_{a}>0, U_{a a}<0, U_{c}>0$ and $U_{c c}<0$. The same holds for the composite good, i.e., $U_{y}>0$ and $U_{y y}<0$. Due to tolerance, the habit stocks affect utility negatively and it is also assumed to do this at an increasing rate, i.e., $U_{G}<0$, $U_{G G}<0, U_{H}<0$ and $U_{H H}<0$. In Chaloupka (1991), past consumption of an addictive good affects utility through its negative effect on health, while Becker and Murphy (1988) assume that in addition to an effect on utility, the habit stock also affects productivity negatively. We follow Chaloupka (1991) and assume only a direct negative health effect from the habit stocks. Since each good is reinforced separately, $U_{a G}>0$ and $U_{c H}>0$. Drinking and smoking are assumed to have no effect on the marginal utility derived from consuming the composite good, and vice versa, i.e., $U_{a y}=U_{c y}=U_{G y}=U_{H y}=0$.

In a situation with two addictive consumption goods, it may be the case that a greater consumption of one of the two goods makes it easier to reduce consumption levels of the other good, or easier to stop using the other good altogether (see Bask and Melkersson, 2000b, for the example of cigarettes and other kinds of nicotine delivery devices). A necessary condition for this to occur is that consumption of one good affects the marginal utility derived from the other good negatively, i.e., $U_{a c}<0$ and $U_{G H}<0$. However, if 
the two addictive consumption goods reinforce each other, for example if drinking and smoking belong to the same psychological "script" (Cameron, 2000, p. 212), we have instead $U_{a c}>0$ and $U_{G H}>0$. Finally, $U_{a c}=U_{a H}=U_{c G}=U_{G H}=0$ is a necessary condition when the alcohol consumption does not depend on the consumption level of cigarettes, and vice versa.

The appropriate budget constraint for the representative consumer is

$$
\sum_{t=1}^{\infty}(1+r)^{-t}\left(p_{a}[t] a[t]+p_{c}[t] c[t]+y[t]\right)=W
$$

where $r>0$ is the constant interest rate, while $p_{a}[t]$ and $p_{c}[t]$ are money prices of alcohol and cigarettes, respectively, and $W$ is the present value of wealth. The money price of the composite good is the numeraire. The representative consumer's problem is to choose $\{a[t]\}_{1}^{\infty},\{c[t]\}_{1}^{\infty}$ and $\{y[t]\}_{1}^{\infty}$ to maximize the discounted stream of utilities:

$$
\max _{a[t], c[t], y[t]} \sum_{t=1}^{\infty}(1+\sigma)^{-t} U(a[t], c[t], G[t], H[t], y[t]),
$$

subject to the budget constraint in eq. (2), the formulation of the habit stocks (see eq. (4) below), and given $a[0], c[0]$ and $y[0]$, where $\sigma>0$ is the constant rate of time preference. Assuming perfect capital markets, the rate of time preference is equal to the interest rate, i.e., $\sigma=r .^{4}$

Since addictive behavior implies linkages in the consumption of the same good over time, it is essential to relax the common assumption of utility being time-separable. The simplest way to relax this assumption is to allow utility in each period to depend on the consumption in that period and in the previous period (Becker et al., 1994). In our case, assuming one habit stock for each consumption good, the simplest formulation is

$$
\left\{\begin{array}{l}
G[t]=a[t-1] \\
H[t]=c[t-1]
\end{array}\right.
$$

In some cases it might be appropriate to possibly allow for one common habit stock, for example if the two addictive consumption goods under scrutiny are legal and illegal cigarettes (Bask and Melkersson, 2000a).

\footnotetext{
4 Note that the assumption of perfect capital markets in combination with perfect foresight, as we assume in our model, implies that the representative consumer can freely borrow and lend money, i.e., consume future (known) income today and save current income for the future. Therefore, we do not include income in our model, but use instead the present value of wealth.
} 
A standard technique used in the literature to derive demand equations is to approximate the instantaneous utility function in the neighborhood of steady-state by a quadratic function in the arguments. If we substitute such a quadratic utility function and eq. (4) into the maximization problem in eq. (3), the following demand equations for alcohol and cigarettes, respectively, can be derived: ${ }^{5}$

$$
\begin{aligned}
a[t]= & \beta_{10}+(1+r) \beta_{11} a[t-1]+\beta_{11} a[t+1]+ \\
& \beta_{12} c[t-1]+\beta_{13} c[t]+\beta_{14} c[t+1]+\beta_{15} p_{a}[t],
\end{aligned}
$$

where $\beta_{10}>0, \beta_{11}>0$ and $\beta_{15}<0$, and

$$
\begin{aligned}
c[t]= & \beta_{20}+(1+r) \beta_{21} c[t-1]+\beta_{21} c[t+1]+ \\
& \beta_{22} a[t-1]+\beta_{23} a[t]+\beta_{24} a[t+1]+\beta_{25} p_{c}[t],
\end{aligned}
$$

where $\beta_{20}>0, \beta_{21}>0$ and $\beta_{25}<0$. Table I in the Appendix presents the signs of the remaining parameters in eq. (5) and eq. (6) under different assumptions of how the two goods are related. The negative sign of $\beta_{15}$ and $\beta_{25}$ follows from the assumption of a positive marginal utility of wealth.

From the rational addiction model a parameter restriction is imposed on each of eq. (5) and eq. (6). In the demand for alcohol, the parameter for lagged consumption equals the effect of lead consumption multiplied by $1+r$. The corresponding parameter restriction is imposed for the demand for cigarettes. Testing this parameter restriction (i.e., testing the null hypothesis of reasonable values of the interest rate, $r$, implied by the estimated parameters, cf., Cameron, 1998) has in the literature been used as a "test" of the validity of the rational addiction model.

The demand equations for alcohol and cigarettes nest several different behaviors. A non-addicted consumer responds only to information in the current period, which means that the parameters for those variables which correspond to the past and the future are zero. An addicted but myopic consumer also responds to past information. Finally, an addicted consumer, who is also rational, responds to past, current, and future information.

The long-run demand elasticities are of interest since these give a measure of the response, between steady-states, to a permanent change in price. Since the model in this

\footnotetext{
${ }^{5}$ See Appendix A in Bask and Melkersson (2000b) for a derivation of eq. (5) and eq. (6), and explicit expressions for the parameters.
} 
paper consists of two addictive consumption goods, cross-price elasticities are also derived and estimated. ${ }^{6}$ Depending on the signs of the cross-price elasticities, it is possible to decide whether the two consumption goods are substitutes or complements.

\section{Previous studies}

There is vast literature on the demand for alcohol and cigarettes, but the present paper will not provide any systematic overview. Instead we refer to the recent overviews in the Handbook of Health Economics (for alcohol, see Cook and Moore, 2000, and for cigarettes, see Chaloupka and Warner, 2000). According to these summaries, studies on cigarette demand have mainly been concerned with starting rates, consumption levels, quitting rates and how these phenomena are related to both socioeconomic variables and policy variables such as taxes and regulations. On the other hand, empirical analyses of alcohol demand have been more focused on the negative external effects of alcohol use at the individual or aggregate level, such as health consequences, effects on crime and on labor market achievements. In the present paper, we will only refer briefly to the literature of particular interest to this paper, i.e., theoretical and empirical studies of demand for more than one addictive consumption good.

Goel and Morey (1995) model the interdependence between cigarette and liquor demand, and use U.S. state level data for a sample of years. Their empirical specification allows for addiction but not rationality. Demand equations for cigarettes and liquor are estimated separately and their interdependence is allowed through cross-price effects. Chaloupka and Laixuthai (1997) use cross-section data and estimate three demand equations, for alcohol, marijuana and "other drugs." Demand is modelled without addiction and the three goods are interdependent through cross-price effects.

Pacula (1997) proposes a theoretical model for a situation with multi-commodity habit formation. The model allows for testing of a joint habit stock of the addictive consumption goods as well as rationality. Pacula (1998) includes estimation of demand for alcohol and marijuana, where the goods are allowed to interact through cross-price effects. Decker and Schwartz (2000) estimate empirical specifications of the demand for alcohol and cigarettes

\footnotetext{
${ }^{6}$ See Appendix A in Bask and Melkersson (2000b) for explicit expressions for the long-run demand elasticities.
} 
in a cross-section data set, where the goods are interdependent through cross-price effects.

Using cross-section data, Su and Yen $(2000)^{7}$ analyze the demand for cigarettes, beer and wine, respectively, with special focus on non-participation, i.e., zero consumption levels. Interdependence between the three addictive consumption goods is discussed in the text and all three goods are estimated simultaneously but no direct cross-price and cross-product effects are included. Farrelly et al. (2001) estimate the demand for cigarettes and marijuana allowing for cross-price effects (a proxy for the marijuana price is used).

van Ours (2001) analyzes the use of alcohol, cannabis, cocaine and tobacco by applying bivariate duration models to a Dutch cross-section data set. Special focus is on whether some addictive consumption goods serve as stepping stones (gateways) to other addictive goods. When accounting for individual heterogeneity there is no evidence of soft drugs serving as stepping stones to hard drugs.

In summary, the empirical papers on multiple addictive consumption goods are usually not based on any formal theoretical framework. Generally, estimations are made for each good separately and, in some cases, allow for cross-price effects. van Ours (2001) is the exception with direct (possibly causal) relations from one addictive consumption good to another, since his interest is in which addictive good is used first and thereby possibly leads to the use of others.

\section{Data and empirical results}

The data used are aggregate annual time series for the Swedish legal alcohol and cigarette markets. ${ }^{8}$ Alcohol consumption is measured in liters of $100 \%$ alcohol and cigarette consumption is measured in standard packs (20 cigarettes), both expressed as consumption per capita aged 15 years or more. As prices for alcohol and cigarettes we use price indices of alcohol and tobacco products, respectively, both deflated by CPI. We will in some estimations use as instruments real income per capita (GDP) (see further below). Descriptive statistics of all variables are shown in Table II in the Appendix, and correlations for quantities and prices are shown in Table III.

In Figure 1, we show per capita consumption of alcohol and cigarettes during the

\footnotetext{
${ }^{7}$ This paper contains many references to similar studies.

${ }^{8}$ We only consider legal sales in the present paper. Bask and Melkersson (2000a) propose a model for demand for legal and illegal cigarettes.
} 
period 1955-1999. The two series both peaked in 1976 and the correlation between them is 0.77. Clearly, cigarette consumption has varied more than alcohol consumption over the years. ${ }^{9}$ In Figure 2, we show alcohol consumption and alcohol price. The correlation between the two series is 0.28 , and a general trend is a slowly increasing real alcohol price. Finally, Figure 3 shows cigarette consumption and its price, where the correlation between the two series is -0.66 . The real cigarette price actually fell during the late 1970s and the early 1980s, while in the 1990s the price has increased quite dramatically. This dramatic price increase has led to decreased legal consumption, but has at the same time caused increased activity on the illegal cigarette market (Bask and Melkersson, 2000a).

Most applications of the rational addiction model have been made using data on levels (see the overview by Cameron, 1998). We know that if the time series are non-stationary, this can produce spurious results (see, e.g., Enders, 1995). Therefore, we have tested all time series with an augmented Dickey-Fuller test following the procedure proposed by Enders (1995, p. 257, where all tests performed use two lags). Almost all time series have a unit root, but when testing the series in first differences, none of the time series has a unit root. Therefore, all estimations are made with all variables (including the instruments) in first differences.

If we express eq. (5) and eq. (6) in first differences, we have

$$
\begin{aligned}
\Delta a[t]= & \beta_{10}^{\prime}+(1+r) \beta_{11} \Delta a[t-1]+\beta_{11} \Delta a[t+1]+ \\
& \beta_{12} \Delta c[t-1]+\beta_{13} \Delta c[t]+\beta_{14} \Delta c[t+1]+\beta_{15} \Delta p_{a}[t],
\end{aligned}
$$

and

$$
\begin{aligned}
\Delta c[t]= & \beta_{20}^{\prime}+(1+r) \beta_{21} \Delta c[t-1]+\beta_{21} \Delta c[t+1]+ \\
& \beta_{22} \Delta a[t-1]+\beta_{23} \Delta a[t]+\beta_{24} \Delta a[t+1]+\beta_{25} \Delta p_{c}[t],
\end{aligned}
$$

where $\Delta a[t]=a[t]-a[t-1]$ and $\Delta c[t]=c[t]-c[t-1]$. If the model is correctly specified, we have $\beta_{10}^{\prime}=0$ and $\beta_{20}^{\prime}=0$. However, in order not to introduce bias in the other parameters, in case of misspecification, we allow for a non-zero intercept in all estimations.

The model in eq. (7) and eq. (8) are estimated as two separate equations. Firstly, the equations are estimated by OLS treating all explanatory variables as exogenous. Secondly,

\footnotetext{
${ }^{9}$ Modelling alcohol and cigarette consumption, respectively, as a function of an intercept, a linear and a quadratic trend produce an $R^{2}$ of 0.574 for alcohol, and an $R^{2}$ of 0.901 for cigarettes.
} 
past and future consumption of both goods are allowed to be endogenous, and we use GMM with two different sets of instruments. The results are presented in Table IV in the Appendix. We see that alcohol demand is consistent with rational addiction, since current alcohol consumption is positively affected by lagged and lead consumption. Also, alcohol demand is negatively affected by its own price, and there is a positive effect from current cigarette consumption. Cigarette demand, however, is not consistent with rational addiction. But two facts are stable for cigarette demand; demand is negatively affected by its own price, and there is a positive effect from current alcohol consumption.

The implied interest rates and long-run demand price elasticities, which follows from the estimates in Table IV, are presented in Table V in the Appendix. Alcohol demand is consistent with rational addiction, and the interest rate is not significantly different from five percent when estimated by OLS and GMM (b). Since cigarette demand is not consistent with rational addiction, we do not calculate any interest rates. The long-run demand elasticities are all negative, and alcohol demand is more elastic than cigarette demand. The cross-price elasticities are negative, i.e., alcohol and cigarettes are complements.

It is expected that alcohol consumption is more sensitive to prices than cigarette consumption, since there are many close substitutes to legal alcohol (legal cross-border shopping, legal home production of wine, illegal home production of liquor and smuggled alcohol). Illegal cigarettes is probably a more "distant" substitute to legal cigarettes than are the substitutes for legal alcohol.

Consumption of alcohol and cigarettes are most probably simultaneous decisions simply because drinking and smoking is often done at the same time. Therefore, we combine eq. (7) and eq. (8), and get the following "semi-reduced" system:

$$
\begin{aligned}
\Delta a[t]= & \beta_{30}+\beta_{31} \Delta a[t-1]+\beta_{32} \Delta a[t+1]+ \\
& \beta_{33} \Delta c[t-1]+\beta_{34} \Delta c[t+1]+\beta_{35} \Delta p_{a}[t]+\beta_{36} \Delta p_{c}[t],
\end{aligned}
$$

and

$$
\begin{aligned}
\Delta c[t]= & \beta_{40}+\beta_{41} \Delta c[t-1]+\beta_{42} \Delta c[t+1]+ \\
& \beta_{43} \Delta a[t-1]+\beta_{44} \Delta a[t+1]+\beta_{45} \Delta p_{c}[t]+\beta_{46} \Delta p_{a}[t] .
\end{aligned}
$$

The parameters in these equations are non-linear functions of the parameters in eq. (7) 
and eq. (8), and the expected signs of them cannot be deduced from the theory. ${ }^{10}$ Instead, we focus on the resulting long-run demand elasticities. As before, we use all variables in first differences.

Firstly, we estimate eq. (9) and eq. (10) as a seemingly unrelated system (SUR), which is the equivalent to OLS but allowing for heteroskedasticity and contemporaneous error correlations in the system. Secondly, we use GMM where both past and future consumption levels are allowed to be endogenous and, as instruments, we use, in GMM (a), lagged and lead prices together with lagged, current and lead income per capita. In GMM (b), we use two lags and two leads of the instruments. The results are shown in Table VI in the Appendix. With the exception of GMM (b), alcohol demand is still positively affected by lagged and lead consumption while cigarette demand is not.

The long-run demand elasticities, which also are presented in Table VI, are generally smaller, in absolute value, compared to those when estimating the equations as separate entities. If we limit the discussion to GMM (b), alcohol demand is still more elastic than cigarette demand. However, it is unclear whether the two consumption goods are complements or not, since it is not possible to decide that on a theoretical basis.

\section{Conclusions}

How well, then, can consumption of alcohol and cigarettes be modeled as rational addiction? We have performed tests of a positive effect on current consumption from both lagged and lead consumption, which is the key feature of the rational addiction framework. We have also tested for reasonable values of the interest rates. In summary, it appears that alcohol demand can quite well be modelled by our model while cigarette demand does not fit the model so well.

Like most other empirical applications of the rational addiction model, we have assumed exogenous prices. It can, of course, be argued that a tax increase is implemented to curb high consumption levels, suggesting endogenous prices. Showalter (1999) discusses the role of endogenous pricing and argues that observed "rational addiction" can be explained, not necessarily by rational consumers, but by myopic consumers in combination with rational and profit maximizing producers of the addictive consumption good.

\footnotetext{
${ }^{10}$ See Appendix A in Bask and Melkersson (2000b) for explicit expressions for the parameters.
} 
How shall we go on from here? The problem of rejecting the rational addiction hypothesis is well put by Laux (2000, p. 429):

"[...] assuming we had better data and that this data would allow us to unequivocally reject the hypothesis of rationality in adult cigarette consumption, how could we measure the extent of this irrationality? Once rationality is rejected, what becomes the appropriate null hypothesis and estimation approach?"

We believe there are several possible explanations for the data not fitting our model so well, which means that rational addiction might still be valid. Firstly, our model is based on utility maximization of a representative consumer. However, in reality there are heterogenous consumers, which means that the model is not appropriate if utilizing a representative consumer is bad as a first approximation. Secondly, consumption of, for example, cigarettes at one particular point in time is the result of a complex flow of individuals who over time start, quit and alter consumption levels. To capture these different decisions might require data on a less aggregated level than we have used (on the individual level or cohort data, which has also been used to model cigarette smoking behavior, see Jiménez-Martín et al., 1998).

Thirdly, our estimations in the present paper have been kept very close to the theoretical framework. We have abstained from adding exogenous variables not included in the model, for example trends. Some of our results which do not favor the rational addiction model might be due to the omission of key variables, such as consumption of other substitutes or complements to alcohol and cigarettes. Another problem with keeping the model very strictly to the theoretical framework is the possible omission of variables describing exogenous shifts in taste.

We hope that the proposed model can be applied to other pairs of addictive consumption goods, such as alcohol and marijuana, and cigarettes and marijuana. For these pairs of goods, there are prior beliefs and knowledge about their possible substitutability or complementarity. It is hoped that new insights will be gained and the possible merits of the rational addiction framework for two addictive consumption goods learnt. 
Rationally Addicted to Drinking and Smoking?

\section{References}

Bask, M. and Melkersson, M. (2000a). Rational Addiction and Smoking when there are Legal and Illegal Cigarettes. Umeå Economic Studies No. 543.

Bask, M. and Melkersson, M. (2000b). Rational Addiction when there are Two Addictive Goods: Cigarettes and Smokeless Tobacco. Umeå Economic Studies No. 545.

Becker, G. S., Grossman, M. \& Murphy, K. M. (1994). An Empirical Analysis of Cigarette Addiction. American Economic Review, 84, 396-418.

Becker, G. S. and Murphy, K. M. (1988). A Theory of Rational Addiction. Journal of Political Economy, 96, 675-700.

Boyer, M. (1983). Rational Demand and Expenditures Patterns under Habit Formation. Journal of Economic Theory, 31, 27-53.

Cameron, S. (1998). Estimation of the Demand for Cigarettes: A Review of the Literature. Economic Issues, 3, 51-71.

Cameron, S. (1999). Rational Addiction and the Demand for Cinema. Applied Economics Letters, 6, 617-620.

Cameron, S. (2000). Nicotine Addiction and Cigarette Consumption: A Psycho-economic Model. Journal of Economic Behavior \& Organization, 41, 211-219.

Chaloupka, F. J. (1991). Rational Addictive Behavior and Cigarette Smoking. Journal of Political Economy, 99, 722-742.

Chaloupka, F. J. and Laixuthai, A. (1997). Do Youths Substitute Alcohol and Marijuana? Some Econometric Evidence. Eastern Economic Journal, 23, 253-275.

Chaloupka, F. J. and Warner, K. E. (2000). The Economics of Smoking. In Culyer A. J. and Newhouse J. P., eds., Handbook of Health Economics, Volume 1B, Ch. 29, North Holland.

Cook, P. J. and Moore, M. J. (2000). Alcohol. In Culyer A. J. and Newhouse J. P., eds., Handbook of Health Economics, Volume 1B, Ch. 30, North Holland.

Decker, S. L. and Schwartz, A. M. (2000). Cigarettes and Alcohol: Substitutes or Complements? NBER Working Paper No. 7535.

Enders, W. (1995). Applied Econometric Time Series. Wiley Series in Probability and Mathematical Statistics, John Wiley \& Sons.

Farrelly, M. C., Bray, J. W., Zarkin, G. A. \& Wendling, B. W. (2001). The Joint Demand 
for Cigarettes and Marijuana: Evidence from the National Household Surveys on Drug Abuse. Journal of Health Economics, 20, 51-68.

Goel, R. K. and Morey, M. J. (1995). The Interdependence of Cigarette and Liquor Demand. Southern Economic Journal, 62, 451-459.

Jiménez-Martín, S., Labeaga, J. M. \& López, A. (1998). Participation, Heterogeneity and Dynamics in Tobacco Consumption: Evidence from Cohort Data. Health Economics, 7, 401-414.

Laux, F. L. (2000). Addiction as a Market Failure: Using Rational Addiction Results to Justify Tobacco Regulation. Journal of Health Economics, 19, 421-437.

Olekalns, N. and Bardsley, P. (1996). Rational Addiction to Caffeine: An Analysis of Coffee Consumption. Journal of Political Economy, 104, 1100-1104.

Orphanides, A. and Zervos, D. (1995). Rational Addiction with Learning and Regret. Journal of Political Economy, 103, 739-758.

van Ours, J. C. (1995). The Price Elasticity of Hard Drugs: The Case of Opium in the Dutch East Indies, 1923-1938. Journal of Political Economy, 103, 261-279.

van Ours, J. C. (2001). On the Dynamics in the Consumption of Alcohol, Tobacco, Cannabis and Cocaine. Working Paper, Tilburg University.

Pacula, R. L. (1997). Economic Modelling of the Gateway Effect. Health Economics, 6, 521-524.

Pacula, R. L. (1998). Does Increasing the Beer Tax Reduce Marijuana Consumption? Journal of Health Economics, 17, 557-585.

Ryder, H. E. Jr. and Heal, G. M. (1973). Optimum Growth with Intertemporally Dependent Preferences. Review of Economic Studies, 40, 1-33.

Showalter, M. H. (1999). Firm Behavior in a Market of Addiction: The Case of Cigarettes. Journal of Health Economics, 18, 409-427.

Su, S.-J. B. and Yen, S. T. (2000). A Censored System of Cigarette and Alcohol Consumption. Applied Economics, 32, 729-737.

Suranovic, S. M., Goldfarb, R. S. \& Leonard, T. C. (1999). An Economic Theory of Cigarette Addiction. Journal of Health Economics, 18, 1-29. 


\section{Appendix}

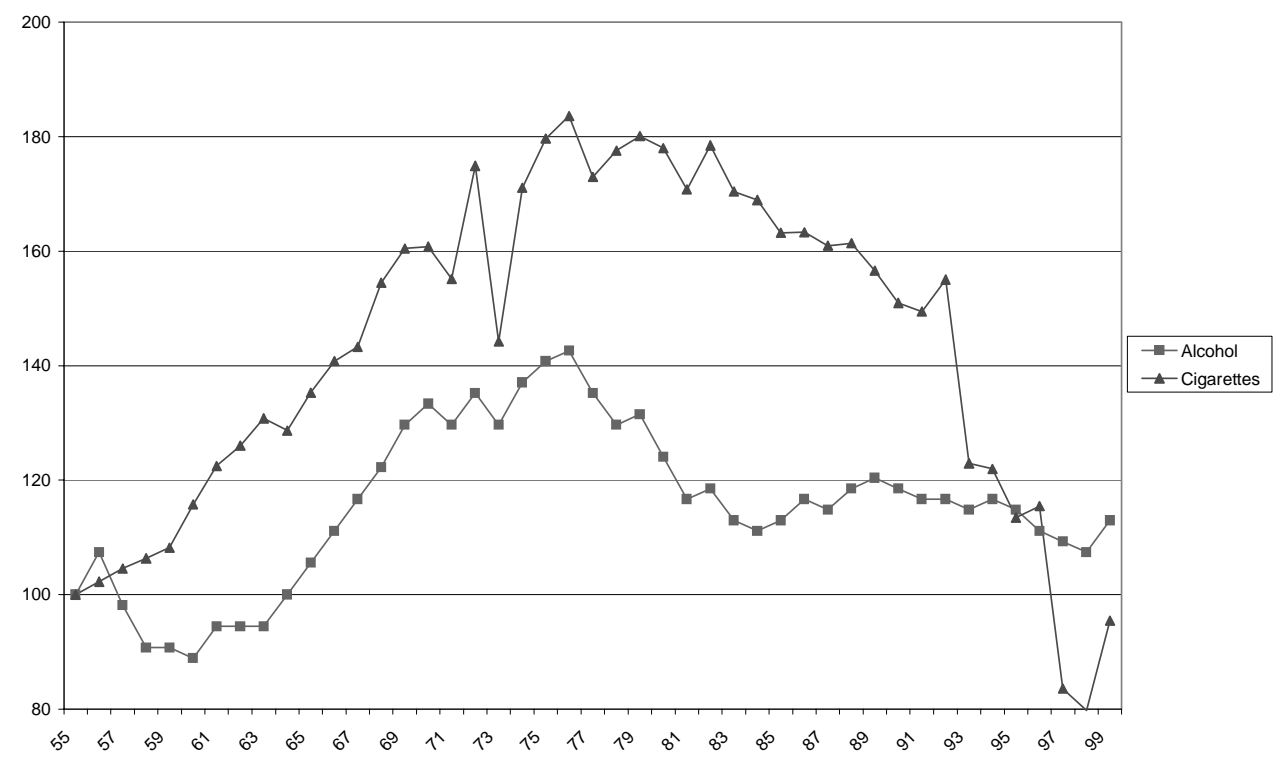

Figure 1: Per capita consumption of alcohol and cigarettes 1955-1999 (1955=100). Correlation: 0.77 . 


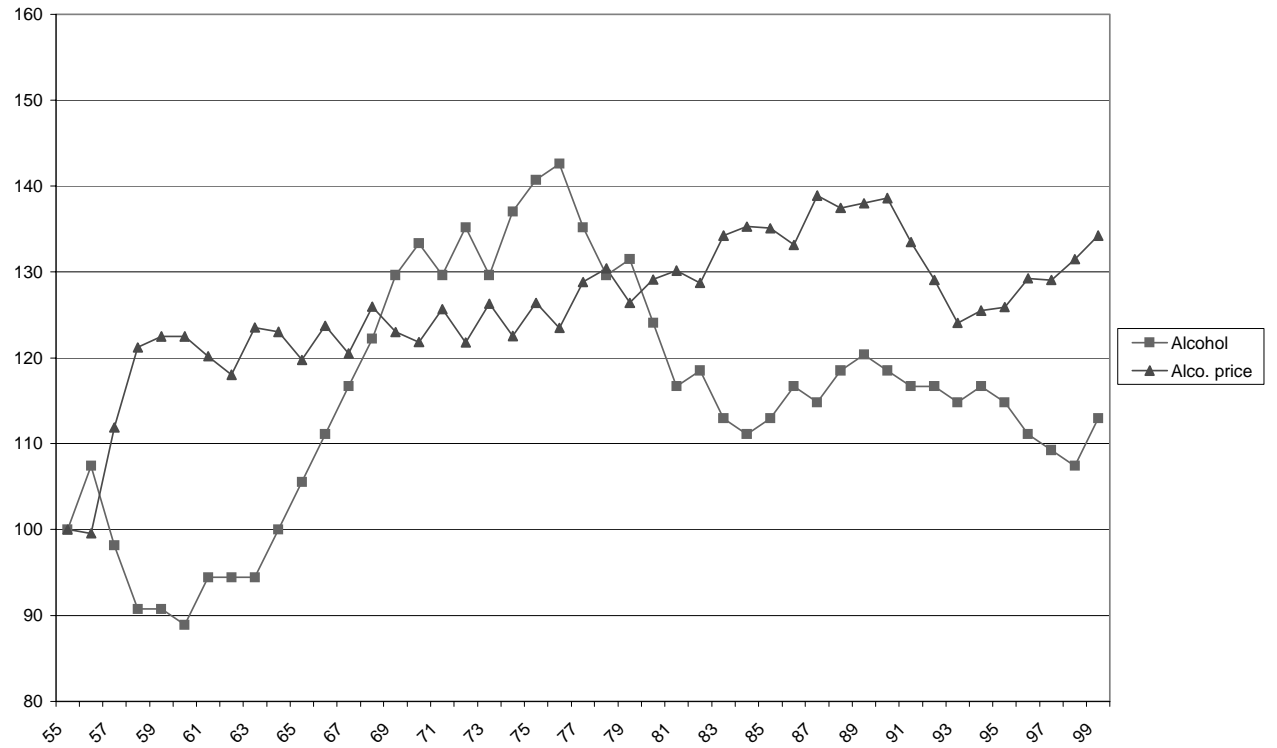

Figure 2: Consumption of alcohol and alcohol price 1955-1999 (1955=100). Correlation: 0.28 .

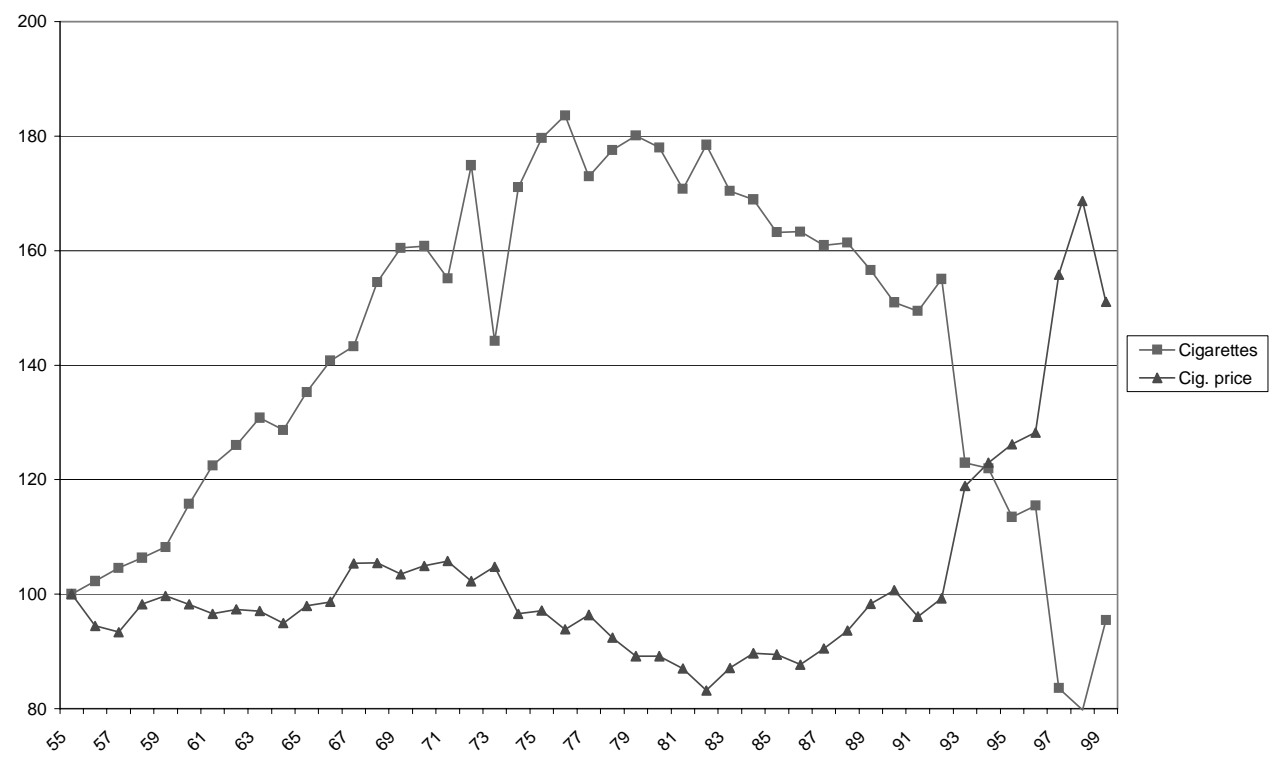

Figure 3: Consumption of cigarettes and cigarette price 1955-1999 (1955=100). Correlation: -0.66 . 
Table I: The signs $(-/ 0 /+)$ of the parameters in the model, when the necessary conditions for the different cases in the table are fulfilled.

\begin{tabular}{lccc}
\hline \hline & Case (1) & Case (2) & Case (3) \\
\hline$\beta_{10}$ & + & + & + \\
$\beta_{11}$ & + & + & + \\
$\beta_{12}$ & undecidable & undecidable & 0 \\
$\beta_{13}$ & - & + & 0 \\
$\beta_{14}$ & undecidable & undecidable & 0 \\
$\beta_{15}$ & - & - & - \\
$\beta_{20}$ & + & + & + \\
$\beta_{21}$ & + & + & + \\
$\beta_{22}$ & undecidable & undecidable & 0 \\
$\beta_{23}$ & - & + & 0 \\
$\beta_{24}$ & undecidable & undecidable & 0 \\
$\beta_{25}$ & - & - & - \\
\hline \multicolumn{4}{l}{ Note: Case (1) is when drinking makes it easier to stay away from or } \\
to stop smoking, and vice versa. Case (2) is when drinking serves to \\
reinforce smoking, and vice versa. Case (3) is when consumption of \\
alcohol and cigarettes do not depend on each other. \\
\hline \multicolumn{4}{l}{} \\
\hline
\end{tabular}

Table II: Descriptive statistics, annual data for 1955-1999.

\begin{tabular}{lrrcrc}
\hline \hline & Mean & Min & (year) & Max & (year) \\
\hline Alcohol/capita & 6.23 & 4.80 & $(60)$ & 7.70 & $(76)$ \\
Cigarettes/capita & 71.41 & 39.81 & $(98)$ & 91.64 & $(76)$ \\
Alcohol price, 1955=1.00 & 1.26 & 0.99 & $(56)$ & 1.39 & $(87)$ \\
Cigarette price, 1955=1.00 & 1.03 & 0.83 & $(82)$ & 1.69 & $(98)$ \\
GDP/capita, 1,000 SEK & 6.89 & 9.13 & $(55)$ & 24.84 & $(99)$ \\
\hline
\end{tabular}

Note: The above figures are from Statistics Sweden. Alcohol is measured in liters of $100 \%$ alcohol and cigarettes are measured in standard packs (20 cigarettes), both per capita aged 15 years or more. SEK refers to its 1955 value. At the min and max values, we give the year in which the min and max is observed.

Table III: Linear correlations for prices and quantities.

\begin{tabular}{lcccc}
\hline \hline Year & Alcohol & Cigarettes & Alcohol price & Cigarette price \\
\hline Alcohol & 1.00 & 0.77 & 0.28 & -0.09 \\
Cigarettes & & 1.00 & 0.40 & -0.66 \\
Alcohol price & & & 1.00 & 0.08 \\
Cigarette price & & & & 1.00 \\
\hline
\end{tabular}


Table IV: Estimation results (parameters) when demand for alcohol and cigarettes are estimated separately. All variables are in first differences.

\begin{tabular}{|c|c|c|c|c|c|c|}
\hline \multirow[t]{2}{*}{ Alcohol } & \multicolumn{2}{|c|}{ OLS } & \multicolumn{2}{|c|}{ GMM (a) } & \multicolumn{2}{|c|}{ GMM (b) } \\
\hline & Par. & $t$ & Par. & $t$ & Par. & $t$ \\
\hline Constant & 0.023 & 0.949 & 0.043 & 2.963 & -0.023 & -1.203 \\
\hline$\Delta a[t-1]$ & 0.249 & 2.282 & 0.208 & 2.112 & 0.179 & 1.951 \\
\hline$\Delta a[t+1]$ & 0.329 & 2.719 & 0.514 & 4.219 & 0.322 & 2.732 \\
\hline$\Delta c[t-1]$ & 0.002 & 0.432 & 0.009 & 2.122 & 0.016 & 2.740 \\
\hline$\Delta c[t]$ & 0.019 & 4.215 & 0.019 & 5.562 & 0.037 & 8.546 \\
\hline$\Delta c[t+1]$ & -0.004 & -0.778 & -0.016 & -3.054 & -0.000 & -0.052 \\
\hline$\Delta p_{a}[t]$ & -3.557 & -5.719 & -3.951 & -8.529 & -3.317 & -8.957 \\
\hline $\bar{R}^{2}$ & 0.625 & & 0.535 & & 0.311 & \\
\hline \multirow[t]{2}{*}{ Cigarettes } & \multicolumn{2}{|c|}{ OLS } & \multicolumn{2}{|c|}{ GMM (a) } & \multicolumn{2}{|c|}{ GMM (b) } \\
\hline & Par. & $t$ & Par. & $t$ & Par. & $t$ \\
\hline Constant & 0.674 & 1.312 & 0.733 & 1.580 & 0.908 & 2.538 \\
\hline$\Delta c[t-1]$ & -0.212 & -2.070 & -0.206 & -1.867 & -0.088 & -0.889 \\
\hline$\Delta c[t+1]$ & -0.215 & -1.918 & -0.117 & -1.549 & -0.083 & -1.197 \\
\hline$\Delta a[t-1]$ & 0.502 & 0.215 & 0.169 & 0.071 & -2.112 & -1.077 \\
\hline$\Delta a[t]$ & 7.107 & 3.064 & 7.679 & 3.108 & 9.083 & 4.479 \\
\hline$\Delta a[t+1]$ & 1.578 & 0.573 & 0.220 & 0.117 & 2.032 & 1.100 \\
\hline$\Delta p_{c}[t]$ & -58.955 & -7.065 & -55.289 & -13.049 & -55.309 & -14.230 \\
\hline $\bar{R}^{2}$ & 0.677 & & 0.668 & & 0.673 & \\
\hline $\begin{array}{l}\text { Note: In th } \\
\text { allowed to } \\
\text { prices, and } \\
\text { two leads o }\end{array}$ & $\begin{array}{l}\text { ed, curre } \\
\text { instrum }\end{array}$ & $\begin{array}{l}\text { and lea } \\
\text { ts. }\end{array}$ & and futur & ce consur & ion of both & $\begin{array}{l}\text { goods are } \\
\text { nd lead } \\
\text { lags and }\end{array}$ \\
\hline
\end{tabular}


Table V: Estimation results (interest rates and long-run demand elasticities) when demand for alcohol and cigarettes are estimated separately. All variables are in first differences.

\begin{tabular}{lcrr}
\hline \hline & OLS & GMM (a) & GMM (b) \\
\hline Interest rate (eq. (7)) & $-24.3 \%$ & $-59.5 \%$ & $-44.4 \%$ \\
$p$-value & 0.522 & 0.003 & 0.264 \\
Interest rate (eq. (8)) & - & - & - \\
$p$-value & - & - & - \\
\hline Elasticities & OLS & GMM (a) & GMM (b) \\
\hline$\partial a / \partial p_{a} \times p_{a} / a$ & -2.31 & -3.88 & -7.16 \\
$\partial c / \partial p_{c} \times p_{c} / c$ & -0.81 & -0.81 & -3.63 \\
$\partial a / \partial p_{c} \times p_{c} / a$ & -0.38 & -0.39 & -4.39 \\
$\partial c / \partial p_{a} \times p_{a} / c$ & -1.30 & -2.06 & -4.81 \\
\hline Note: The interest rate can be estimated in two different ways, but \\
is only given when rational addiction is present. The interest rates \\
and elasticities are calculated using more decimals than those \\
presented in Table IV. The $p$-value refers to an F-test of the null \\
hypothesis of r=0.05. See Table IV for explanations of GMM (a) \\
and (b).
\end{tabular}


Table VI: Estimation results (parameters and long-run demand elasticities) when demand for alcohol and cigarettes are estimated simultaneously. All variables are in first differences.

\begin{tabular}{|c|c|c|c|c|c|c|}
\hline \multirow[t]{2}{*}{ Alcohol } & \multicolumn{2}{|c|}{ SUR } & \multicolumn{2}{|c|}{ GMM (a) } & \multicolumn{2}{|c|}{ GMM (b) } \\
\hline & Par. & $t$ & Par. & $t$ & Par. & $t$ \\
\hline Constant & 0.029 & 0.984 & 0.056 & 1.646 & -0.038 & -2.270 \\
\hline$\Delta a[t-1]$ & 0.289 & 2.260 & 0.381 & 2.450 & -0.152 & -1.903 \\
\hline$\Delta a[t+1]$ & 0.412 & 2.902 & 1.045 & 5.435 & 0.395 & 4.288 \\
\hline$\Delta c[t-1]$ & -0.002 & -0.431 & -0.004 & -0.912 & 0.038 & 12.021 \\
\hline$\Delta c[t+1]$ & -0.010 & -1.696 & -0.066 & -3.589 & -0.015 & -3.463 \\
\hline$\Delta p_{a}[t]$ & -3.612 & -4.938 & -2.308 & -3.521 & -4.948 & -9.908 \\
\hline$\Delta p_{c}[t]$ & -0.805 & -1.780 & -0.291 & -0.811 & -0.195 & -0.883 \\
\hline \multirow[t]{2}{*}{ Cigarettes } & \multicolumn{2}{|c|}{ SUR } & \multicolumn{2}{|c|}{ GMM (a) } & \multicolumn{2}{|c|}{ GMM (b) } \\
\hline & Par. & $t$ & Par. & $t$ & Par. & $t$ \\
\hline Constant & 0.695 & 1.180 & 1.495 & 1.621 & -0.934 & -3.429 \\
\hline$\Delta c[t-1]$ & -0.239 & -2.071 & -0.366 & -2.276 & 0.397 & 10.129 \\
\hline$\Delta c[t+1]$ & -0.330 & -2.719 & -1.135 & -3.569 & -0.290 & -6.563 \\
\hline$\Delta a[t-1]$ & 2.150 & 0.836 & 2.157 & 0.608 & -7.418 & -9.988 \\
\hline$\Delta a[t+1]$ & 4.920 & 1.723 & 9.817 & 2.279 & 0.643 & 0.503 \\
\hline$\Delta p_{c}[t]$ & -65.338 & -7.176 & -45.795 & -4.555 & -60.518 & -27.389 \\
\hline$\Delta p_{a}[t]$ & -1.195 & -0.081 & 21.552 & 1.592 & 5.102 & 0.846 \\
\hline Elasticities & \multicolumn{2}{|c|}{ SUR } & \multicolumn{2}{|c|}{ GMM (a) } & \multicolumn{2}{|c|}{ GMM (b) } \\
\hline$\partial a / \partial p_{a} \times p_{a} / a$ & \multicolumn{2}{|c|}{-2.04} & \multicolumn{2}{|c|}{6.55} & \multicolumn{2}{|c|}{-1.05} \\
\hline$\partial c / \partial p_{c} \times p_{c} / c$ & \multicolumn{2}{|l|}{-0.65} & \multicolumn{2}{|l|}{-1.03} & \multicolumn{2}{|l|}{-0.77} \\
\hline$\partial a / \partial p_{c} \times p_{c} / a$ & \multicolumn{2}{|l|}{-0.13} & \multicolumn{2}{|l|}{-1.83} & \multicolumn{2}{|l|}{-0.31} \\
\hline$\partial c / \partial p_{a} \times p_{a} / c$ & \multicolumn{2}{|l|}{-0.82} & \multicolumn{2}{|l|}{2.89} & \multicolumn{2}{|l|}{0.79} \\
\hline
\end{tabular}

